\title{
REVIEW.
}

\section{"A SIXTH VENEREAL DISEASE."}

By H. S. Stannus. Bailliere, Tindall \& Cox, London, 1933. Size $5 \frac{1}{2} \times 9$. pp.xii +270 , Plates 9. Price 12s. 6d.

In this monograph entitled "A Sixth Venereal Disease " the author identifies climatic bubo of tropical and sub-tropical climates with lymphogranuloma inguinale of temperate climates. Chronic ulcer and elephantiasis of the genito - ano - rectal region and inflammatory stricture of the rectum are, perhaps less convincingly, attributed to the same filterable virus transmitted by venereal contact. The virus itself is experimentally transmissable to certain species of monkeys and several laboratory animals. The evidence for identifying these diverse conditions rests mainly on Frei's intra-cutaneous test which, as Hellerström has shown, may also be positive in prostitutes showing no inguinal adenitis or other signs of disease.

In lymphogranuloma inguinale the primary lesion generally consists of single or multiple tiny herpetiform vesicles or ulcers which are painless and not tender to the touch, occurring on the glans penis, prepuce, vulva and fourchette and appearing 3 days to 3 weeks after coitus. In a few days to 6 weeks adenitis also follows, the inguinal glands on one or both sides enlarging and often producing stiffness and aching in the groin: multiple gland in- volvement with peri-adenitis follows, culminating generally in suppuration with sinus formation. The iliac glands are as a rule also involved, but rarely suppurate. Constitutional symptoms are frequent and include fever, rigors, sweats, nausea, vomiting and loss of weight. Erythema nodosum is stated to be not infrequent. The author points out that spontaneous cure occurs with much greater frequency than was formerly supposed, and that, in evaluating treatment, sufficient care has not been exercised regarding the stage of the disease at which therapy was commenced. No specific drugs are available, but nonspecific protein therapy introduced by Hanschell has yielded favourable results. Excision of the glands in the early stages may be successful but later, where extensive extirpation of large masses of glands becomes necessary, elephantiasis of the scrotum is recorded as following surgical intervention.

This monograph, especially in its historic aspects, is of great interest ; its publication is opportune for the disease is becoming more frequently recognised in Europe and the subject is one unfamiliar to the general members of the profession.

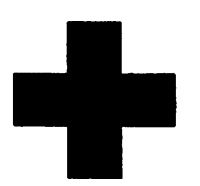

\section{BRITISH RED CROSS SOCIETY CIINIC FOR RHIUMATISM \\ Peto Place, Marylebone Road, N.W.1.}

The Clinic is open for the reception of patients who must be recommended by their own doctors. Evening treatment available. Private Patients department open 9 a.m. to 5 p.m. Treatment by appointment only.

Courses of Lectures and Demonstrations are given by the Honorary Medical Staff under the auspices of the Fellowship of Medicine. Clinical Assistantships available.

For full information apply to the Secretary, at above address. 